\title{
Physicians not fazed by AZT guidelines
}

Washington. Physicians in the United States have been advised by an expert panel to confer thoroughly with patients and then to use their own discretion in prescribing antiretroviral drugs, such as AZT, to patients who are outwardly healthy but infected with HIV.

The new guidelines replace those issued in 1990, which recommended routine prescription of AZT in all cases where the count of the marker CD4 cell has fallen below 500 last week by an independent panel convened by the National Institute of Allergy and Infectious Diseases (NIAID) and chaired by Merle Sande, the chief of medical services at San Francisco General Hospital.

"Doctors and patients should work as a team to design a treatment strategy that is both clinically sound and appropriate for each individual patient's needs, priorities and circumstances in daily life", Sande says. The panel, whose findings are widely seen as a response to April's preliminary report of the Anglo-French Concorde trial (see Nature 362, 483; 1993), emphasized that "the choice to accept or decline antiretroviral therapy ultimately rests with the patient", an per $\mathrm{mm}^{3}$. The new guidelines were drawn up

NIAID statement said.

The panel still recommends antiretroviral drugs for patients who report with symptoms of AIDS, with AZT recommended as the first line of treatment. But for patients who have low CD4 counts but no actual symptoms, the panel leaves prescription of the drug to the discretion of the physician.

Physicians working with HIV patients in major US cities say that the guidelines largely reflect their current practice of not prescribing AZT to patients on the basis of low CD4 counts alone. "I've always been somewhat cautious about prescribing these drugs," says Dr Donald Abrams, assistant director of AIDS practice at the San Francisco General Hospital. "The guidelines won't change my practice at all."

But Abrams criticises the panel for failing to say anything about the need for more clinical trials to establish better treatment options. His concerns are echoed by $\mathrm{Dr}$ Joseph Sonnabend, an AIDS physician practising in New York, who says: "The situation we are in now is a mess." Sonnabend says that many members of the panel were involved in earlier guidelines since proven to be premature. "A little self-criticism would

\section{Hopes for pan-European network}

London. European research may soon have a continent-wide system of high-speed computer links as robust as its counterpart in the United States; those responsible for the national academic computer networks in 12 European countries are launching a new company to do just that.

Known as Delivery of Advanced Network Technology for Europe Ltd (or DANTE), the company is being set up by the members of the Réseaux Associés pour la Recherche Européenne (or RARE), a forum of national networking organizations based in Amsterdam. It will operate from Cambridge, England, with the goal of providing a comprehensive pan-European network for the academic, government and commercial research community as well as developing high-speed links to the United States. It will be accessed through and paid for by each country's own national academic network service.

DANTE will take over responsibility for various existing European networking services such as EuropaNET, a recently established 2 megabit per second network funded by the European Commission. The new company is also putting together a bid to the commission for a contract to establish a 34 m.b.p.s. network (enough capacity for video-conferencing) which would bring Europe-wide communication closer to the speeds available in the United States.

Several individual members of RARE are already developing their own high-speed networks. In Britain, for example, work is currently under way on a 140 m.b.p.s. network SuperJANET, funded by a $£ 5$ million grant from the government through the Higher Education Funding Councils.

Many of the individual networks have already developed bilateral links, both with counterparts in Europe and with the various research networks in the United States. But progress at the European level has been disappointing, partly because of the complexities of dealing with highly political telecommunications agencies and partly because of the high costs of long-distance data-links, which can be five or six times more expensive than in the United States.

DANTE is seen as an attempt to finesse these problems. It hopes to act as a central source of technical advice, to use contacts built up through member organizations to address political issues and to provide a single applicant for EC funds, as well as to negotiate with US and other networks.

Supporters of DANTE hope that it may also attract funding by offering the academic community as a guinea-pig for more ambitious plans to develop a pan-European system of "information highways", an idea parallel to that being pushed by vice-president Albert Gore in the United States, which was proposed two weeks ago by the president of the Commission, Jacques Delors.

David Dickson not have been out of place", he says.

Spencer Cox of the New York-based Treatment Action Group (TAG) says that the main impact of the guidelines will be in small-town America, and in inner-city clinics where patients may get little personal attention.

In a separate development, a National Commission on AIDS set up by statute four years ago issued its final report, attacking "governors, mayors, members of Congress, corporate executives, community or religious leaders" and "previous presidents" for failing to take a lead in tackling the AIDS epidemic.

Colin Macilwain

President Clinton has named Kristine Gebbie, a health care administrator in Washington state and former nurse, as his AIDS policy coordinator. AIDS researchers and activists welcomed Gebbie's reputation as a conciliator, but doubted if she would carry the clout to tackle powerful vested interests.

\section{FDA joins market}

Washington. The US Food and Drug Administration (FDA) is putting flesh on the bones of a programme that will, it hopes, allow it to raise over $\$ 300$ million in the next five years by charging drug companies for certain services it provides.

FDA's authority is the Prescription Drug User Fee Act, enacted last October (see Nature 359, 567; 1992). The money raised in user fees will boost current budgets and allow FDA to employ extra staff to speed the review of new drug applications.

FDA, which is about to begin invoicing companies, estimates that about 150 companies and 2,000 products will be caught in its net, but 70 per cent of the revenue is expected to come from 20 of the biggest US pharmaceutical companies. The agency expects to raise $\$ 36$ million in the first year of the programme, rising to $\$ 84$ million in 1997 with annual increases in the fees charged.

The money will be used to employ 620 extra staff -280 for the Center for Drug Evaluation and Research, 300 for the Center for Biologics Evaluation and Research and the remaining 40 for the Office of Regulatory Affairs. An additional 80 staff will be required to handle the invoicing of companies and the collection of fees.

The overall objective is to meet performance goals defined in the statute, which industry may monitor more zealously than the Congress. FDA's interim goal is to deal with 55 per cent of new drug applications and product licence applications within twelve months in 1994, and to increase that proportion to 90 per cent in 1997.

Diane Gershon 